RUNNING HEAD: Intergroup fears and concerns for contact

\begin{abstract}
Aims. Driven by the literature on pluralistic ignorance, our research investigates fear of appearing racist, being rejected, discriminated, and disinterest in intergroup contact as antecedents of contact and outgroup attitudes, focusing on attributional differences between the majority and minority group perspectives.
\end{abstract}

Methods. Questionnaires were distributed in schools in Northern Italy. Participants were 400 Italian and 141 immigrant high-school students.

Results. The results showed that lack of interest in contact was the strongest predictor of contact for the majority group. For the minority group, fear of rejection emerged as the strongest predictor. The majority group attributed the minority to avoid contact most strongly due to the fear that they would be rejected, and the minority group perceived it was due to the majority not being interested in contact.

Conclusion. Our research contributes to understanding the divergent concerns majority and minority groups have in relation to intergroup contact, and discusses the importance of tackling these concerns.

Keywords: Fear of rejection; interest in contact; pluralistic ignorance; intergroup contact; attitudes; adolescents, group representations. 


\section{Intergroup fears and concerns among minority and majority groups: Implications for contact and attitudes}

Engaging in intergroup contact is of paramount importance, as under the right conditions contact can reduce prejudice and improve intergroup relations (Hodson \& Hewstone, 2013; Pettigrew \& Tropp, 2008). Engaging in positive intergroup contact however, presents challenges as people may not know 'how' to interact with others who have different identities or backgrounds. For example, people may have a fear of offending outgroup members and being perceived as racist (Sue, 2013), or they may have negative expectations about the contact experience, for example fearing that they will be rejected or taken advantage of by the outgroup (Shelton \& Richeson, 2005). Such fears and concerns may deter people from engaging in intergroup contact and impair outgroup attitudes. In other words, although research generally considered intergroup contact as a starting point for prejudice reduction, people often engage in contact having fears and expectations that may contribute to determine the contact experience and its consequences.

When a situation arises where intergroup contact can occur, group members make a decision whether or not to engage in or avoid contact. When the outgroup is unfamiliar, ingroup members are more likely to experience anxiety leading up to the interaction (Stephan, 2014; Stephan \& Stephan, 2000), rely on perceived norms to determine their behavior (Sechrist \& Stangor, 2007) or adhere to homophily (Al Ramiah, Schmid, Hewstone, \& Floe, 2015). Complying with norms of perceived social consensus to guide intergroup behavior may occur even when the ingroup member's personal attitudes toward the outgroup differ from what they believe the group's attitudes as a whole are (Shelton \& Richeson, 2005). For instance, the individual ingroup member may want to interact with the outgroup but avoid contact because their ingroup is known to avoid that particular outgroup. This can be explained by 'pluralistic ignorance', a phenomenon that describes a situation where an individual holds an opinion but mistakenly assumes that the majority of the group holds different opinions (Halbesleben, Wheeler, \& Buckley, 2007). 
With our research we suggest that pluralistic ignorance inhibits the opportunity to reduce prejudice as it limits the action potential for positive intergroup contact to even occur. This research extends the literature on pluralistic ignorance in several ways. Firstly, we investigate novel divergent attributions majority and minority groups make for avoiding contact in an intergroup context with an adolescent sample. Specifically, we investigate the fear of appearing racist, being rejected, discriminated, and disinterest in intergroup contact. Secondly, we test a novel model that examines these attributions as antecedents of contact and outgroup attitudes, mediated by preference for group categorization. Finally, we investigate own and perceived outgroup attributions at the individual ingroup and outgroup level.

\section{Pluralistic ignorance and intergroup contact}

Pluralistic ignorance is a psychological process involving two social cognitive errors, one being that an individual mistakenly believes that the majority of the group holds an opposite belief to his/her own (error of social comparison), and secondly that the individual confidently believes that the perceived difference in belief is accurate (accuracy error) (Halbesleben et al., 2007). In the context of intergroup relations, pluralistic ignorance refers to the inaction to interact in intergroup settings based on attributions people make about their own ingroup as well as the outgroup (Shelton \& Richeson, 2005). That is, exclusionary behavior may be based on what people perceive is a belief held by the ingroup and/or the outgroup, and not their own personal belief. Inaction to engage in intergroup contact has been observed in a variety of real-world and experimental contexts, resulting in re-segregation of majority and minority groups in classroom or social settings, which has negative implications for reducing prejudice (Al Ramiah et al., 2015). Sue (2013) explored people's fears regarding intergroup interactions and found that during racial dialogues in the classroom between Whites and Blacks there was anxiety around violating 'rules' of politeness. This resulted in individuals excluding themselves from the conversations as they were fearful of rejection or social isolation. 
Previous research has shown that ingroup members differ in justifications for their own, versus the outgroup's, avoidance of intergroup contact (Shelton \& Richeson, 2005). In their seminal work, Shelton and Richeson investigated the concerns that different groups have when approaching contact, focusing on the attributions that are made to justify contact avoidance. Specifically, the authors measured the fear of rejection by the outgroup and lack of interest in contact in a sample of Blacks and Whites in the United States. In a series of seven studies, the authors found that there were clear differences between Whites' and Blacks' perceived desire for contact at the individual and group level (see also Tropp \& Bianchi, 2006). That is, both Whites and Blacks personally wanted or believed their ingroup wanted more contact with the outgroup, than they perceived outgroup members wanted with the ingroup. Additionally, it was found that there were consistent divergent attributions made by Whites and Blacks regarding contact avoidance, providing evidence for the occurrence of pluralistic ignorance. The results demonstrated that the ingroup attributed own avoidance to the fear of being rejected due to ingroup race, whereas the ingroup perceived the outgroup avoided contact due to lack of interest in contact.

Shelton and Richeson's (2005) research provides three noteworthy findings. Firstly, that pluralistic ignorance predicts whether the ingroup will engage in contact with the outgroup. Secondly, that majority and minority groups attribute contact avoidance to divergent factors. Thirdly, that pluralistic ignorance can be attenuated by changing the misperceived group level norms, for example by telling an individual group member that their friend (from the same ingroup) feels positively about outgroup members. This seminal work provides a solid starting point to allow the further examination of implications of divergent intergroup concerns on intergroup contact and, in turn, outgroup attitudes.

\section{Intergroup concerns: Implications for contact and attitudes}

Of central importance to the current research is investigating factors that inhibit intergroup contact. It is also important to further explore differential perceptions and fears regarding contact, 
and the subsequent relationship with attitudes, in order to diffuse pluralistic ignorance and encourage ethnic dialogue and intergroup contact. From the perspective of ingroup members, outgroup members are generally perceived to have a negative image of the ingroup (Mendez, Gómez, \& Tropp, 2007; Vorauer et al., 1998). Group members may behave in ways that confirm the other group's perceptions and this may lead to contact avoidance and conflict. Previous research, for example, has found that Whites anticipated that minority groups would perceive them as prejudiced, selfish, and closed-minded (Vezzali, 2017; Vorauer \& Kumhyr, 2011). This resulted in the ingroup being self-conscious and self-critical of their actions. Similar research from the minority group's perspective has shown that Blacks perceived that they would be judged based on negative stereotypes about their identity, which in turn limited their interracial contact (Branscombe, Schmidt, \& Harvey, 1999; Shelton \& Richeson, 2005).

Social pressure to comply with political correctness concerning, for instance, race-related issues, affects intergroup attitudes and behaviors (Van Boven, 2000). Social norms provide a difficult barrier to overcome as they are internalized at the group level and can dictate protocol for academia (objectivity in the classroom), politeness (avoiding offensive or uncomfortable topics), and color-blindness (judged based on internal attributes), all of which facilitate silence around race/ethnicity (Sue, 2013). Studies have shown that when engaging in race talk in a classroom setting, White students responded to the topic with anxiousness and cautiousness because they were not only afraid to appear racist but also afraid of realizing they harbor racism, and wanted to avoid further conversation on the topic. Minority group students, on the other hand, became angry and frustrated as they felt victim of microaggressions and were commonly stereotyped based on their skin color (Sue, 2013; Sue, Rivera, Capodilupo, Lin, \& Torino, 2010). Goff, Steele and Davies (2008) showed that Whites' interracial distancing (in this research, from Black conversation partners) was in fact not predicted by prejudice but it correlated with the "White racist" stereotype. 
Thus, in our research we tested whether fear of appearing racist is a key predictor of contact and attitudes in the case of the majority group.

From the perspective of minority groups, fear of being discriminated against can also have negative consequences for intergroup relations. Tropp (2007) explored relations among Whites and Blacks in the United Stated and found that for Blacks who perceived considerable discrimination, intergroup contact did not yield significant positive effects. Generally, minority group members' perceptions and fear of discrimination have been found to worsen their interracial attitudes, while majority groups' attitudes are not affected by such concerns (see Monteith \& Spicer 2000; Tropp, 2007). Therefore, in our study we tested whether fear of being discriminated predicts contact and attitudes in the case of the minority group.

Shelton and Richeson (2005) further raise an important point, that in addition to the usual anxiety experienced when strangers encounter one another, interracial interactions are also fraught with anxiety related to the history of prejudice, racism, oppression and discrimination that may exist between the groups. If majority group members feel uncomfortable to speak about race due to concerns of appearing racist, they are more likely to lack familiarity with the outgroup, which has been shown to moderate interracial contact effects (Sechrist \& Stangor, 2007). Additionally, fear of appearing prejudiced has been found to increase majority group members' stress responses during the contact experience (Trawalter, Adam, Chase-Lansdale, \& Richeson, 2012), which can impair the beneficial effects of contact (Stephan \& Stephan, 1985). Accordingly, minority group members' fear of being discriminated against renders them more likely to avoid contact or suffer from high levels of anxiety that will impact on the contact experience (Stephan \& Stephan, 1985).

Fear of rejection, as posited by Shelton and Richeson (2005), is also key in the context of pluralistic ignorance. Generally, rejection is perceived differently in intergroup versus intragroup contexts, with rejection by the outgroup yielding more anger (Mendes, Berry, Major, McCoy, \& Blascovich, 2008). Shapiro, Baldwin, Williams and Trawalter (2011) examined the role of fear of 
rejection in intergroup interactions and showed that White participants who saw pictures of a Black man with a White friend expressed higher concern of being rejected by the outgroup, which led to an inclination to reject the outgroup (see also Wout, Murphy, \& Steele, 2010). The authors further discussed the importance of mitigating fear of rejection in order to avoid detrimental outcomes for intergroup relations. Exploring own and perceived outgroup fear of rejection is crucial when aiming to identify barriers to contact and positive attitudes, so we examine fear of rejection in the case of both the majority and minority group.

Interest in contact is also important to examine when aiming to understand barriers of contact engagement in intergroup settings. Paolini, Wright, Dys-Steenbergen and Favara (2016) found that willingness for and interest in contact (predicted by self-expansion expectancies) is related to various types of direct and indirect contact. Alreshoud and Koeske (1997) demonstrated that personal desire for contact predicts intergroup contact in the context of Arab and American students. Tropp and Bianchi (2006) suggested that minority group members express interest in having intergroup contact only when they believe that diversity is valued by the majority group, indirectly pointing to the importance of considering pluralistic ignorance. Mendez, Gomez and Tropp (2007) showed that perceiving that the outgroup's attitude toward the ingroup is negative deters own interest in intergroup contact (for those participants high in prototypicality). More closely related to our research, Al Ramiah et al. (2015) found that White (majority) participants attributed both own and Asian (minority) participants' contact avoidance in school settings (i.e., in the school cafeteria) more to lack of interest than to fear of rejection. They further found that Asian participants attributed own contact avoidance to fear of rejection and lack of interest while the outgroup's avoidance was attributed to lack of interest only. We thus test interest in contact as a predictor of contact and attitudes in the case of both the majority and minority group.

\section{The current research}


Previous research suggests that majority and minority groups are concerned with how they will be perceived by the outgroup (Shelton, Richeson, \& Vorauer, 2006; Sue, 2013) and that there is a self-other bias regarding the attributions that people make for avoiding contact (Al Ramiah et al., 2015; Shelton \& Richeson, 2005). More specifically, we build on previous work from Shelton and Richeson (2005), Al Ramiah et al. (2015) and Sue (2010), and for the first time we simultaneously test four predictors as antecedents of quality and quantity of intergroup contact and outgroup attitudes, from both the majority and minority group perspective: fear of appearing racist (for the majority group), fear of rejection (for the minority group), fear of discrimination (for both the majority and minority group), and lack of interest in contact (for both the majority and minority group).

At the same time, we test one-group representations as a mediator of the contact-attitudes relationship. Acknowledging that the predictors we test may highlight intergroup boundaries, we seek to test if contact in fact helps bring groups together by increasing one-group representations. Categorization into social groups is a process linked to intergroup bias (Tajfel \& Turner, 1979; Turner, 1985). Gaertner and Dovidio (2000) suggested that categorization can in fact be used to promote superordinate, inclusive identities, which can then minimize intergroup boundaries. That is, by recategorizing group members into a common group at a superordinate level, former outgroup members obtain a one-group representation and intergroup barriers become less meaningful. At this level of categorization, different groups conceive themselves as part of an inclusive singular group, rather than two separate groups, and prejudice is reduced (Capozza, Trifiletti, Vezzali, \& Favara, 2013; Eller \& Abrams, 2004; Gonzalez \& Brown, 2003). A salient one-group identity has been shown to promote positive outgroup evaluations and to mediate the relationship between intergroup contact and its positive outcomes (Eller et al., 2003; Nier et al., 2016; Ward \& Rust, 2001). Eller and Abrams (2004), for example, showed that high quality contact (i.e., contact as friends) predicts 
one-group representation, leading to more positive attitudes and less perceived distance from the outgroup.

Investigating attributions that hinder intergroup contact is a timely area of social psychological research. Global migration trends are rapidly changing with large increases in African and Asian populations coming to Europe (Connor, 2018). This trend is apparent in Italy, where a recent influx of migration has changed the demographics of the Italian population. According to the ISTAT data (2017) there are 3.714.137 people from countries outside the European Union who live in Italy. As a result, discourse focused on issues around contact and multiculturalism has become prominent in Italy. The current research investigates the phenomenon of pluralistic ignorance and related antecedents of contact, in the context of intergroup relations among a sample of Italian and immigrant adolescents in Italy. Avoiding intergroup contact can be damaging, especially in school settings as this is an impressionable time to form interracial acceptance (Al Ramiah et al., 2015; Sue et al., 2010). We therefore focus on educational settings and conduct our research with a sample of school students.

In line with previous research (e.g., Shelton \& Richeson, 2005), we hypothesize that there will be differences in the attributions that individuals make for their own, and the outgroup's preference for contact (pluralistic ignorance). Specifically, we predict that the Italian sample will attribute more disinterest in contact to the outgroup than to the self, and will express more fear of appearing racist and being rejected than outgroup fear of being discriminated and rejected. We further predict that the immigrant sample will attribute more fear of discrimination and rejection to the self than to the outgroup, and more disinterest in contact to the outgroup than to the self. More central to our research, we further expect that such (self and outgroup) fears and concerns regarding contact will predict intergroup contact, which will in turn be associated with more positive outgroup attitudes via increased one-group representations (Eller \& Abrams, 2004).

\section{Method}




\section{Participants and Procedure}

Participants were 541 first year high-school students (264 females; $M_{\text {age }}=14.51 ; S D=$ 0.79). They were recruited from five schools located in Northern Italy. The Italian sample included 400 students $\left(194\right.$ females; $\left.M_{\text {age }}=14.36 ; S D=0.65\right)$, the immigrant sample included 141 students (70 females; $\left.M_{\mathrm{age}}=14.95 ; S D=0.99\right)$. Regarding the country of origin, the largest part of the immigrant sample came from Africa (45.6\%), followed by Asia (22.8\%), Eastern Europe (22.1\%) and South America (6\%) (mixed origin, 3.4\%). Distinction between Italians and immigrants was made based on indications by the schools and by taking into account the family background of students (i.e., both Italian parents for Italian participants; both foreign parents for immigrant participants).This distinction is commonly used in research considering data collected in Italy, especially concerning data from both majority and minority groups (e.g., Vezzali, Cadamuro, Versari, Giovannini, \& Trifiletti, 2015; Visintin, Voci, Pagotto, \& Hewstone, 2017).

Participants were administered a questionnaire written in Italian language during classes. The target outgroup varied according to participants' group: the Italians' outgroup was immigrants; the immigrants' outgroup was Italians.

\section{Measures}

Antecedents of contact. For all items below, the response scale ranged from 1 (never) to 5 (very often); the other steps were $2=$ rarely; $3=$ sometimes; $4=$ often.

\section{Majority group}

To assess Fear of appearing racist, participants were asked how often, when they have contact with the outgroup, they are afraid of appearing racist. Fear of rejection was measured by asking participants how often, when they have contact with the outgroup, they are afraid of being rejected. Lack of interest in contact was assessed by asking participants how often they avoid contact due to lack of interest in interacting with the outgroup.

The three previous items were rephrased in order to measure the respective attributions regarding the outgroups' stance. In particular, respondents were asked how often outgroup members 
avoid contact because a) they are afraid of being discriminated (Attribution of fear of discrimination); b) they are afraid of being rejected (Attribution of fear of being rejected); c) they are not interested in contact (Attribution of lack of interest in contact).

\section{Minority group}

To assess Fear of being discriminated against, participants were asked how often, when they have contact with the outgroup, they are afraid of being discriminated. Fear of being rejected and Lack of interest in contact were assessed using the same items as for the majority group.

The three previous items were again rephrased in order to measure the respective attributions regarding the outgroups' stance. This time, minority group participants were asked how often outgroup members avoid contact because a) they are afraid of appearing racist (Attribution of fear of appearing racist); b) they are afraid of being rejected (Attribution of fear of being rejected); c) they are not interested in contact (Attribution of lack of interest in contact).

Quantity of contact. Participants responded to the following items: "With how many immigrants [Italians] from your school do you usually spend time at school?" (the response scale ranged from $1=$ none to $5=$ more than six); the other steps were $2=2 ; 3=4 ; 4=6$ ), "How much contact do you have with immigrants [Italians] from your school?" (the response scale ranged from $1=$ none to $5=$ a lot); "During the day, how often do you interact with immigrants [Italians] from your school?" (the response scale ranged from $1=$ never to $5=$ very often; the other steps were $2=$ rarely; $3=$ sometimes $; 4=$ often. The reliability of the measure was satisfactory $(\alpha=.72)$.

Quality of contact. Participants evaluated interactions with the outgroup on four bipolar items (e.g., competitive/cooperative; rude/kind) adapted from Capozza et al., 2013. On the 5-step scale, 1 was assigned to the negative pole (for example, competitive), 5 to the positive pole (for example, cooperative), while 3 was the neutral point (neither...nor...). The reliability of the measure was good $(\alpha=.83)$.

Group representations. In line with literature on the common ingroup identity model (Gaertner \& Dovidio, 2000), group representations were assessed with four items targeting levels of 
categorization (see e.g., Eller \& Abrams, 2004). In particular, participants were asked: "In your school, to what extent do you perceive Italians and immigrants" as a) "members of different groups?" (Two groups); b) “separate individuals?" (Individuals); c) "members of the same group, namely students of the school?" (One group); d) "members of different groups, and, at the same time, members of the larger group of students of the school?" (Dual identity). Participants provided their answers on a 5-step scale $(1=$ not at all; $5=$ very much $)$.

Outgroup attitudes. Five semantic differential items (e.g., positive/negative, desirable/undesirable) adapted from Wright, Aron, McLaughlin-Volpe and Ropp's (1997) were used to assess outgroup evaluation. On the 5-step scale, 1 was assigned to the negative pole, and 5 to the positive pole; 3 was the neutral point. The reliability of the measure was good $(\alpha=.89)$.

\section{Results}

\section{Preliminary analyses}

Means and standard deviations for the Italian and immigrant samples are provided in Table 1; correlations among variables are provided in Table 2.

As can be seen from Table 1, Italian participants expressed more fear of appearing racist during contact compared to immigrant participants' fear of being discriminated. Similarly, Italians tended to avoid contact due to lack of interest more than immigrants did. Immigrant students were afraid of being rejected more often than Italians.

Italians reported to a greater extent that outgroup members avoid contact because they are afraid of being rejected and discriminated against than immigrants did; conversely, immigrants reported more than Italians that outgroup members avoid contact because they are not interested in it.

Overall, contact was positive for both groups, since means were significantly different from the neutral point of the scale, $t \mathrm{~s} \geq 16.36, p \mathrm{~s}<.001, d \mathrm{~s}>0.81$. In line with previous research (Vezzali, Giovannini, \& Capozza, 2010), immigrants reported more frequent contact with Italians than vice versa. No differences emerged between Italians and immigrants on group representations 
(although there are nonsignificant tendencies for Italians to prefer one-group and for immigrants to prefer dual identity representations, in line with the larger categorization literature; Dovidio, Gaertner, \& Saguy, 2007).

\section{Pluralistic ignorance}

In order to detect the presence of pluralistic ignorance, a 2 (Group: Italians vs. Immigrants) x 2 (Antecedents of Contact: Self vs. Outgroup Attributions) x 3 (Type: Fear of Appearing Racist/Discrimination vs. Fear of Rejection vs. Lack of Interest in Contact) repeated measures ANOVA, with Group as between level factor and the latter two as within level factors, was employed. As expected, the two-way interaction, Antecedents of Contact x Type, $F(2,538)=6.57$, $p<.002, \eta_{\mathrm{p}}^{2}=.02$, was qualified by the three-way interaction, Group $\mathrm{x}$ Antecedents of Contact $\mathrm{x}$ Type, $F(2,538)=72.39, p<.001, \eta^{2} \mathrm{p}=.21$.

Regarding the Italian sample (means are reported in Table 1), the Antecedents of Contact $\mathrm{x}$ Type interaction was significant, $F(2,398)=121.00, p<.001, \eta^{2}=.38$. Simple effects analyses showed discrepancies considering Fear of Appearing Racist/Discrimination, $F(1,399)=139.11, p<$ $.001, \eta_{\mathrm{p}}^{2}=.26$, and Fear of Rejection, $F(1,399)=413.83, p<.001, \eta_{\mathrm{p}}^{2}=.51$; specifically, Italians perceived that the outgroup is more fearful of being discriminated and rejected than the individual perception of appearing racist and being rejected (i.e., higher values for Attributions scores compared to Self scores). On the other hand, no differences emerged for Lack of Interest in Contact, $F(1,399)=1.63, n s, \eta_{\mathrm{p}}^{2} \approx .00$. In this case, Italian participants reported similar scores for their and the outgroup's (dis)interest in contact.

For the immigrant sample, there was a significant two-way interaction, $F(2,139)=11.30, p$ $<.001, \eta^{2} \mathrm{p}=.14$. In particular, discrepancies emerged considering Fear of Appearing Racist/Discrimination, $F(1,140)=23.95, p<.001, \eta_{\mathrm{p}}^{2}=.15$, and Lack of Interest in Contact, $F(1$, 140) $=67.41, p<.001, \eta^{2}=.32$. In both cases, Self scores were significantly smaller than Attributions scores, denoting that immigrant participants perceived greater outgroup fear of appearing racist than self fear of discrimination, and greater outgroup (than self) disinterest in 
contact. Finally, no significant differences emerged regarding Fear of Rejection, $F(1,140)=1.81$, $n s, \eta^{2}=.01 .^{1}$

\section{Main analyses}

In order to further test our hypotheses, we used structural equation modeling with latent variables (SEM). For the two contact dimensions (quality and quantity) and for outgroup attitudes we averaged the respective items into two parcels following the suggestions by Little and collaborators (Little, Cunningham, Shahar, \& Widaman, 2002); for the latent constructs loading on a single indicator we fixed the error to zero.

We tested the model separately for the Italian and for the immigrant sample. Antecedents of contact were included at the first level, quality and quantity at the second level, the four group representations at the third level, outgroup attitudes at the fourth level. In the model, we included correlations between antecedents (first-level of the model), between quantity and quality of contact (second-level of the model), and between group representations (third-level of the model). Moreover, we included the direct paths from antecedents to group representations and to outgroup attitudes, and from quantity and quality of contact to outgroup attitudes. Mediation was tested by employing bootstrapping procedures with 5,000 resamples.

To evaluate the goodness-of-fit of the models we used the chi-square test statistic $\left(\chi^{2}\right)$, the comparative fit index (CFI), the root-mean-square error of approximation (RMSEA), and the standardized root-mean-square residual (SRMR). A satisfactory fit is expressed by a CFI value greater than .95 , an RMSEA value smaller or equal to .06, an SRMR smaller or equal to .08 (Hu \& Bentler, 1999), and a $\chi^{2} / d f$ ratio smaller than 3 (Kline, 2010).

\section{Italian sample}

The model (Figure 1) showed an excellent fit to the data, $\chi^{2}(36)=39.64, p=.31 ; \chi^{2} / d f=$ $1.10 ; \mathrm{CFI}=1.00 ; \mathrm{RMSEA}=.01 ; \mathrm{SRMR}=.01$. Specifically, fear of being rejected was positively associated with quality of contact, while lack of interest in contact was negatively associated with both quality and quantity of contact and with outgroup attitudes. In addition, lack of interest in 
contact was negatively associated with outgroup attitudes. Regarding the other contact antecedents, demonstrating the importance of considering attributions to the outgroup, we found a positive association between the outgroup's fear of being rejected and the two-groups representation, and a negative association between the attribution to the outgroup of lack of interest in contact and outgroup attitudes. Moreover, quality of contact was negatively related with the two-groups identity representations, and positively associated with the one-group representation and with outgroup attitudes. In addition, the one-group representation was positively linked with outgroup attitudes.

Concerning indirect effects (Table 3), fear of rejection and lack of interest in contact were associated with outgroup attitudes (positively and negatively, respectively) via greater quality of contact and one-group representation. In addition, fear of rejection was indirectly associated with more negative separate individuals and two-groups representations, and indirectly associated with higher one-group representation, via increased quality of contact. In contrast, lack of interest in contact was indirectly associated with lower one-group representation and higher separate individuals and two-groups representation via reduced quality of contact.

\section{Immigrant sample}

The model (Figure 2) showed an excellent fit to data, $\chi^{2}(36)=46.43, p=.11 ; \chi^{2} / d f=1.29$; $\mathrm{CFI}=0.99 ; \mathrm{RMSEA}=.04 ; \mathrm{SRMR}=.03$. As can be seen in Figure 2, fear of being discriminated positively associated with quality of contact. In contrast, fear of rejection was negatively related to both quality and quantity of contact, and positively related to the perceptions that Italians and immigrants are two-groups and separate individuals. Avoiding contact because of lack of interest was negatively associated with quality of contact and positively associated with the dual identity representation. In addition, attributions of contact avoidance because of lack of interest (from Italians) was positively associated with the separate individuals representation. Finally, a positive relation emerged between quality of contact and outgroup attitudes.

With respect to indirect effects (Table 4), fear of being discriminated was indirectly associated with more positive outgroup attitudes via increased quality of contact. In contrast, we 
found negative indirect effects from fear of rejection and lack of interest in contact to more negative outgroup attitudes via reduced quality of contact ${ }^{2}$.

\section{Discussion}

The current study examined differences in attributions that the ingroup and outgroup make for their own and perceived outgroup justifications for (avoiding) contact. Building on research from Shelton and Richeson (2005), Al Ramiah et al. (2015), and extending the qualitative themes uncovered by Sue (2013), for the first time we tested the factors of own and perceived outgroup fear of rejection and lack of interest in contact, and additionally for the majority group, fear of being racist, and for the minority group, fear of being discriminated against. We simultaneously tested these as antecedents of quality and quantity of contact, and outgroup attitudes, via group representations.

The results confirmed our hypothesis that there are differences between own and outgroup attributions for intergroup contact, although differences emerged in some unexpected ways. Italians attributed greater fear of rejection to the outgroup than to the self, and perceived greater outgroup concern about being discriminated than self concern about appearing racist. On the other hand, immigrants attributed more disinterest in contact to the outgroup than the self, and also expressed more perceived outgroup fear of appearing racist than self concern about being discriminated. As for outgroup attributions specifically, Italians attributed immigrants to avoid contact most strongly due to the fear that they would be rejected, and immigrants perceived that it was due to the Italians not being interested in contact. We also found that lack of interest in contact for the Italians emerged to be the strongest predictor of contact, whereas for immigrants the strongest predictor was their own fear of rejection. Itis interesting that fear of rejection emerged as the strongest predictor of the immigrant group's (lack of) contact with the Italians, as the Italians appeared to have identified this factor as the main concern inhibiting contact from the perspective of the outgroup. These findings are in line with research that has shown that group members typically avoid other groups 
due to intergroup anxiety or lack of confidence for intergroup contact (Sechrist \& Stangor, 2007). Research has also shown that stereotypes of perceived group attitudes can influence norms and attitudes for ingroup and outgroup members (Yzerbet, Judd, \& Muller, 2008). It is therefore possible that preexisting stereotypes inform attributions regarding the outgroup's stance, which then feeds into the contact experience.

We also found that categorization, for the minority group, did not mediate the path to improved attitudes. Literature related to minorities and intergroup contact has shown that minorities are more resistant to one-group representations, which may explain why we found no mediation via categorization for the minority group (Dovidio et al., 2007). Future research should aim to further understand the underlying processes that explain why intergroup fears and concerns predict contact and attitudes for majorities and minorities.

We should note that some results were in contrast to our predictions. For Italians, fear of being rejected was positively associated with outgroup attitudes, via greater quality of contact and one-group perceptions. Possibly, Italian participants were motivated to have contact (as indirectly shown by the fact that their lack of interest in contact was rather low), and fear of rejection may have helped them place more effort on being accepted and have positive intergroup interactions. Similarly, immigrants who were afraid of being discriminated may have been motivated to disconfirm negative stereotypes that could likely prevent their acceptance in the intergroup interaction (also in this case, lack of interest in contact was low). As a consequence, perhaps they made more effort to be accepted. In other words, participants' motivation for high quality contact may be a key determinant of approach behaviors and the contact experience. Future research should examine the interplay between motivation and contact expectations in intergroup contexts.

As this research employed a correlational design, we cannot infer causality from the factors we tested against contact, group representations, and outgroup attitudes. Future research should experimentally manipulate the relevant factors to investigate whether the attributions predicting 
contact are causing the effects we observed, and to understand which attribution most strongly predicts outgroup contact and attitudes. In addition to experimentally manipulating the factors, it would be beneficial to investigate potential moderators and mediators of the proposed model. Prototypicality, for example, would be a worthwhile moderator to investigate in relation to pluralistic ignorance, as previous research has shown that those high in prototypicality reported higher anxiety as well as less interest in the outgroup, and perceived that the outgroup did not want contact with the ingroup (Mendez et al., 2007).

Additionally, it would be worthwhile to investigate whether pluralistic ignorance accounts for minority-minority contact avoidance as well. Al Ramiah et al. (2015), for example, showed that racial segregation occurs among minority groups as well, for instance Blacks and Asians. Research on inter-minority relations is still scarce so there is ample scope to examine the role of pluralistic ignorance as well as key variables (for example, contact and group representations) in seeking to provide a comprehensive account of intergroup dynamics.

As fear of rejection emerged as a strong predictor in the model for both the Italian and immigrant group, for own as well as perceived outgroup contact, future research should consider investigating these factors in the context of meta-perceptions (i.e., how one group perceives to be viewed by another group). For example, fear of rejection could be tackled with the positive metaperception of ingroup acceptance. That is, if the self or ingroup fears rejection from the outgroup, research can explore ways of creating positive meta-perceptions that highlight the outgroup's desire for contact (Stathi, Di Bernardo, Vezzali, Pendleton, \& Tropp, 2020). This would be worthwhile to investigate as previous research has shown that salient positive meta-perceptions lead to increased positive feelings and acceptance in interracial contexts (Vezzali, 2017). It would also be worthwhile for future research to take a more thorough approach on intergroup contact and investigate how factors such as body language can account for contact avoidance and subsequent outgroup attitudes. For example, people may appear unfriendly or fail to initiate contact via closed body language, 
facial expressions, or lack of eye contact and this may perpetuate the cycle of stereotypes, maintenance of prejudice, and contact avoidance (Philipot \& Yabar, 2005). Future research should aim to identify ways to signal openness for contact as this may attenuate some of the anxiety and fear related to avoiding intergroup interactions.

There is limited research investigating pluralistic ignorance with samples of adolescents (Al Ramiah et al., 2015). Future research should explore a developmental trajectory to see if younger children also experience similar concerns. Future investigation on this topic focusing on young children is important because it may help address factors that predict negative attitudes and suggest how to overcome barriers to acceptance and shared identity, before intergroup anxiety and prejudice begin to form. Previous research indicated that being unfamiliar with outgroups leads to anxiety and avoidance (Sechrist \& Stangor, 2007; Sue, 2013); therefore, if we make group memberships a more familiar topic of conversation at a young age then we may be able to prevent contact-related concerns from forming in early school years.

At this point we need to acknowledge that in our research we referred to Italians and immigrants as general categories, and were not able to distinguish among subgroups within these categories. For example, the immigrant sample consisted of participants from various different cultural backgrounds. Although we did not have sufficient statistical power to conduct analyses separately for different subgroups, future research can take this into account and provide more nuanced and informative findings. Similarly, it would be worth exploring whether people of immigrant background who are born and raised in a specific national context differ in their fears and concerns regarding intergroup contact from those who are first generation immigrants.

The findings from this research are of high relevance to school settings, as they highlight the importance of intergroup contact among students and the need to offer students opportunities to get to know and interact with each other. Future research should focus on developing strategies that promote inclusive identities in early school settings as this has been shown to increase the desire to 
learn about outgroups (Eller \& Abrams, 2004). It would also be important for educators and researchers to work together toward creating and evaluating methods to encourage interest in contact between students of different backgrounds, and dialogue around ethnic and cultural issues. 


\section{Footnotes}

1. Adding Gender (Male vs. Female) as a between-participants factor in the ANOVAs did not affect the results.

2. A multiple group analyses (using the $\chi^{2}$ difference test, Satorra $\&$ Bentler, 2001) was also employed in order to investigate the moderator effect of gender. According to the results, the model did not converge, meaning that gender was not involved in the tested relations. 


\section{References}

Al Ramiah, A., Schmid, K., Hewstone, M., Floe, C. (2015). Why are all the White (Asian) kids sitting together in the cafeteria? Resegregation and the role of intergroup attributions and norms. The British Journal of Social Psychology, 54, 100-124. doi:10.1111/bjso.12064

Alreshoud, A., \& Koeske, G. F. (1997). Arab students' attitudes toward and amount of social contact with Americans: A causal process analysis of cross-sectional data. The Journal of Social Psychology, 137, 235-246. doi:10.1080/00224549709595434

Branscombe, N., Schmitt, M., \& Harvey, R. (1999). Perceiving pervasive discrimination among African Americans: Implications for group identification and well-being. Journal of Personality and Social Psychology, 77, 135-149. doi:10.1037/0022-3514.77.1.135

Capozza, D., Trifiletti, E., Vezzali, L., Favara, I. (2013). Can intergroup contact improve humanity attributions? International Journal of Psychology, 48, 527-541. doi:10.1080/00207594.2012.688132

Connor, P. (2018, March 22). At least a million sub-saharan Africans moved to Europe since 2010. Retrieved from http://www.pewglobal.org/2018/03/22/at-least-a-million-sub-saharan-africansmoved-to-europe-since-2010/

Dovidio, J., \& Gaertner, S. (2010). Intergroup bias. In S. T. Fiske, D. T. Gilbert, \& G. Lindzey (Eds.), Handbook of social psychology, 5th ed. (pp. 1084-1121). Hoboken, NJ: John Wiley \& Sons Inc. Retrieved from http://search.ebscohost.com/login.aspx?direct=true \&db=psyh\&AN=2010-03506029\&site=ehost-live 
Dovidio, J., Gaertner, S., \& Saguy, T. (2007). Another view of 'We': Majority and minority group perspectives on a common ingroup identity. European Review of Social Psychology, 18, 296330. doi:10.1080/10463280701726132

Eller, A., Abrams, D. (2004). Come together: longitudinal comparisons of Pettigrew's reformulated intergroup contact model and the common ingroup identity model in Anglo French and Mexican American contexts. European Journal of Social Psychology, 34, 229-256. doi:10.1002/ejsp.194

Gaertner, S. L., \& Dovidio, J. F. (2000). Reducing intergroup bias: The common ingroup identity model. New York, NY, US: Psychology Press.

Gaertner, S., Dovidio, J., Anastasio, P., Bachman, B., \& Rust, M. (1993). The common ingroup identity model: Recategorization and the reduction of intergroup bias. European Review of Social Psychology, 4, 1-26. doi:10.1080/14792779343000004

Goff, P., Steele, C., \& Davies, P. (2008). The space between us: Stereotype threat and distance in interracial contexts. Journal of Personality and Social Psychology, 94, 91-107. doi:10.1037/0022-3514.94.1.91

Gonzalez, R., \& Brown, R. (2003). Generalization of positive attitude as a function of subgroup and superordinate group identifications in intergroup contact. Journal of Experimental Psychology, 33, 195-214. doi:10.1002/ejsp.140

Halbesleben, J., Wheeler, M., Ronald, B., (2007). Understanding pluralistic ignorance in organizations: application and theory. Journal of Managerial Psychology, 22, 65-83. doi:10.1108/02683940710721947

Hodson, G., \& Hewstone, M. (2013). Advances in intergroup contact. New York, NY: Psychology Press. 
Instituto Nationale di Statiztica (ISTAT). (2017). Annual report 2017: The state of the nation. Retrieved from https://www.istat.it/en/archivio/201296

Little, T. D., Cunningham, W. A., Shahar, G., \& Widaman, K. F. (2002). To parcel or not to parcel: Exploring the question, weighing the merits. Structural Equation Modeling, 9, 151-173. doi:10.1207/S15328007SEM0902_1

Mendes, W. B., Major, B., McCoy, S., \& Blascovich, J. (2008). How attributional ambiguity shapes physiological and emotional responses to social rejection and acceptance. Journal of Personality and Social Psychology, 94, 278-291. doi:10.1037/0022-3514.94.2.278

Méndez, E., Gómez, Á., \& Tropp, L. R. (2007). When metaperceptions are affected by intergroup processes. International Journal of Psychology and Psychological Therapy, 7, 237-250.

Monteith, M. J., Ashburn-Nardo, L., Voils, C. I., \& Czopp, A. M. (2002). Putting the brakes on prejudice: On the development and operation of cues for control. Journal of Personality and Social Psychology, 83, 1029-1050. doi:10.1037/0022-3514.83.5.1029

Nier, J. A., Gaertner, S. L., Dovidio, J. L., Banker, B. S., Ward, C. M., \& Rust, M. C. (2001). Changing interracial evaluations and behavior: The effects of a common group identity. Group Processes and Intergroup Relations, 4, 299-316. doi:10.1177/1368430201004004001

Paolini, S., Wright, S., Dys-Steenbergen, O., Favara, I. (2016). Self-expansion and intergroup contact: Expectancies and motives to self-expand lead to greater interest in outgroup contact and more positive intergroup relations. Journal of Social Issues, 72, 450-471. doi:10.1111/josi.12176 
Pettigrew, T. F., \& Tropp, L. R. (2008). How does intergroup contact reduce prejudice? Metaanalytic tests of three mediators. European Journal of Social Psychology, 38, 922-934. doi:10.1002/ejsp.504

Philippot, P., \& Yabar, Y. (2005). Stereotyping and action tendencies attribution as a function of available emotional information. European Journal of Social Psychology, 35, 517-536. doi:10.1002/ejsp.269

Shapiro, J. R., Baldwin, M., Williams, A. M., \& Trawalter, S. (2011). The company you keep: Fear of rejection in intergroup interaction. Journal of Experimental Social Psychology, 47, 221-227. doi:10.1016/j.jesp.2010.10.006

Shelton, J. N., \& Richeson, J. A. (2005). Intergroup Contact and Pluralistic Ignorance. Journal of Personality and Social Psychology, 88(1), 91-107. https://doi.org/10.1037/0022-3514.88.1.91

Shelton, J., Richeson, J., \& Bergsieker, H. (2009). Interracial friendship development and attributional biases. Journal of Social \& Personal Relationships, 26, 179-193. doi:10.1177/0265407509106707

Shelton, J. N., \& Richeson, J. A, \& Vorauer, J. D. (2006). Threatened identities and interethnic interactions. European Review of Social Psychology, 17, 321-358. doi:10.1080/10463280601095240

Sechrist, B \& Stangor, C. (2007) When are intergroup attitudes based on perceived consensus information? Social Influence, 2, 211-235. doi:10.1080/15534510701459068

Stathi, S., Di Bernardo, G. A., Vezzali, L., Pendleton, S., \& Tropp, L. R. (2020, accepted). Do they want contact with us? The role of intergroup contact meta-perceptions on positive contact and attitudes. Journal of Community and Applied Social Psychology. 
Stephan, W. G. (2014). Intergroup anxiety: Theory, research, and practice. Personality and Social Psychology Review, 18, 239-255. doi:10.1177/1088868314530518

Stephan, W. G., \& Stephan, C. W. (1985). Intergroup anxiety. Journal of Social Issues. 41(3), 157-175. doi:10.1111/j.1540-4560.1985.tb01134.x

Stephan, W. G., \& Stephan, C. W. (2000). An integrated threat theory of prejudice. In S. Oskamp (Ed.), Claremont symposium on applied social psychology (pp. 23-46). Hillsdale, NJ: Erlbaum.

Sue, D. (2013). Race talk: The psychology of racial dialogues. American Psychologist, 68, 663-672. doi:10.1037/a0033681

Sue, D., Rivera, D., Capodilupo, C., Lin, A., \& Torino, G. (2010). Racial dialogues and White trainee fears: Implications for education and training. Cultural Diversity and Ethnic Minority Psychology, 16, 206-214. doi:10.1037/a0016112

Tajfel, H., \& Turner, J. C. 1986. The social identity theory of intergroup behavior. In S. Worchel \& W. G. Austin (Eds.), The psychology of intergroup relations (pp. 7-24). Chicago: Nelson-Hall.

Trawalter, S., Adam, E. K., Chase-Lansdale, P. L., \& Richeson, J. A. (2012). Concerns about appearing prejudiced get under the skin: Stress responses to interracial contact in the moment and across time. Journal of Experimental Social Psychology, 48, 682-693. doi:10.1016/j.jesp.2011.12.003

Tropp, L. R. (2007). Perceived discrimination and interracial contact: Predicting interracial closeness among Black and White Americans. Social Psychology Quarterly, 70, 70-81. doi:10.1177/019027250707000108

Tropp, L., \& Bianchi, R. (2006). Valuing diversity and interest in intergroup contact. Journal of Social Issues, 62, 533-551. doi:10.1111/j.1540-4560.2006.00472.x 
Turner, J. C. (1985). Social categorization and the self-concept: A social cognitive theory of group behaviour. In E. J. Lawler (Ed.), Advances in Group Processes 2 (pp. 77-122). Greenwich, CT: JAI Press.

Van Boven, L. (2000). Pluralistic ignorance and political correctness: The case of affirmative action. Political Psychology, 21, 267-276. doi:10.1111/0162-895X.00187

Vezzali, L. (2017). Valence matters: Positive meta-stereotypes and interethnic interactions. The Journal of Social Psychology, 157, 247-261. doi:10.1080/00224545.2016.1208140

Vezzali, L., Cadamuro, A., Versari, A., Giovannini, D., \& Trifiletti, E. (2015). Feeling like a group after a natural disaster: Common ingroup identity and relations with outgroup victims among majority and minority young children. British Journal of Social Psychology, 54, 519-538. doi: $10.1111 /$ bjso.12091

Vezzali, L., Drury, J., Versari, A., \& Cadamuro, A. (2016). Sharing distress increases helping and contact intentions via social identification and inclusion of the other in the self: Children's prosocial behaviour after an earthquake. Group Processes \& Intergroup Relations, 19(3), 314327. https://doi.org/10.1177/1368430215590492

Vezzali, L., Giovannini, D., \& Capozza, D. (2010). Longitudinal effects of contact on intergroup relations: The role of majority and minority group membership and intergroup emotions. Community and Applied Social Psychology, 20, 462-479. doi:10.1002/casp.1058

Visintin, E. P., Voci, A., Pagotto, L., \& Hewstone, M. (2017). Direct, extended, and mass-mediated contact with immigrants in Italy: Their associations with emotions, prejudice, and humanity perceptions. Journal of Applied Social Psychology, 47, 175-194. doi: 10.1111/jasp.12423

Vorauer, J., \& Kumhyr, S. M. (2001). Is this about you or me? Self- versus other-directed judgments and feelings in response to intergroup interaction. Personality and Social Psychology Bulletin, 27, 706-719. doi:10.1177/0146167201276006 
Vorauer, J. D., Main, K. J., \& O’Connell, G. B. (1998). How do individuals expect to be viewed by members of lower status groups? Content and implications of meta-stereotypes.

Journal of Personality and Social Psychology, 75, 917-937. doi:10.1037/0022-3514.75.4.917

Wout, D. A., Murphy, M. C., \& Steele, C. M. (2010). When your friends matter: The effect of white students' racial friendship networks on meta-perceptions and perceived identity

contingencies. Journal of Experimental Social Psychology, 46, 1035-1041.

doi;10.1016/j.jesp.2010.06.003

Wright, S. C., Aron, A., McLaughlin-Volpe, T., \& Ropp, S. A. (1997). The extended contact effect: Knowledge of cross-group friendships and prejudice. Journal of Personality and Social Psychology, 73, 73-90. doi: 10.1037/0022-3514.73.1.73

Yzerbyt, V. Y., Judd, C. M., \& Muller, D. (2009). How do they see us? The vicissitudes of metaperception in intergroup relations. In S. Demoulin, J.-P. Leyens, \& J. F. Dovidio (Eds.), Intergroup misunderstandings: Impact of divergent social realities (pp. 63-83).

New York, NY, US: Psychology Press. 
Table 1. Means (standard deviations) of the constructs.

\begin{tabular}{|c|c|c|c|c|}
\hline Measures & $\begin{array}{l}\text { Italians } \\
(N=400)\end{array}$ & $\begin{array}{l}\text { Immigrants } \\
(N=141)\end{array}$ & $t$ & Cohen's $d$ \\
\hline $\begin{array}{l}\text { Fear of appearing racist (Italians) / being } \\
\text { discriminated (immigrants) }\end{array}$ & $2.65(1.19)$ & $2.23(1.13)$ & $3.61 * * *$ & 0.36 \\
\hline Fear of being rejected & $1.93(1.01)$ & $2.20(1.12)$ & $2.53 *$ & 0.25 \\
\hline Lack of interest in contact & $2.82(1.23)$ & $2.09(1.13)$ & $6.20 * * *$ & 0.62 \\
\hline $\begin{array}{l}\text { Attribution of fear of appearing racist } \\
\text { (Italians) / being discriminated } \\
\text { (immigrants) }\end{array}$ & $3.48(1.06)$ & $2.81(1.14)$ & $6.31 * * *$ & 0.61 \\
\hline Attribution of fear of being rejected & $3.39(1.03)$ & $2.37(1.18)$ & $9.06 * * *$ & 0.92 \\
\hline Attribution of lack of interest in contact & $2.73(0.97)$ & $3.10(1.13)$ & $3.47 * * *$ & 0.35 \\
\hline Quality of contact & $3.74(0.91)$ & $3.79(0.93)$ & 0.51 & 0.05 \\
\hline Quantity of contact & $2.72(0.90)$ & $3.58(1.04)$ & $8.73 * * *$ & 0.88 \\
\hline Individuals & $2.66(1.27)$ & $2.77(1.26)$ & 0.91 & 0.09 \\
\hline Two groups & $2.42(1.31)$ & $2.48(1.31)$ & 0.41 & 0.04 \\
\hline One group & $3.52(1.27)$ & $3.28(1.30)$ & 1.93 & 0.19 \\
\hline Dual identity & $2.84(1.19)$ & $2.99(1.19)$ & 1.29 & 0.13 \\
\hline Outgroup attitudes & $3.21(0.88)$ & $3.52(0.86)$ & $3.70 * * *$ & 0.36 \\
\hline
\end{tabular}

Note. All measures had a 5-step scale. ${ }^{*} p<.05$. $* * * p<.001$. 
Table 2. Correlations between constructs for the Italian $(N=400$, below the diagonal $)$ and immigrant sample $(N=141$, above the diagonal).

\begin{tabular}{|c|c|c|c|c|c|c|c|c|c|c|c|c|c|}
\hline & 1 & 2 & 3 & 4 & 5 & 6 & 7 & 8 & 9 & 10 & 11 & 12 & 13 \\
\hline \multicolumn{14}{|l|}{$\begin{array}{l}\text { 1. Fear of appearing racist } \\
\text { (majority)/ }\end{array}$} \\
\hline $\begin{array}{l}\text { Fear of discrimination } \\
\text { (minority) }\end{array}$ & - & $.46^{* * *}$ & $.23^{* *}$ & $.28^{* * *}$ & .09 & $.30 * * *$ & .02 & -.05 & .07 & .08 & .08 & $.18^{*}$ & .04 \\
\hline 2. Fear of being rejected & $.17^{* * *}$ & - & $.30 * * *$ & $.23 *$ & .15 & $.33^{* * *}$ & $-.26 * *$ & -.14 & $.20^{*}$ & $.24 * *$ & $-.18^{*}$ & $.22 *$ & -.13 \\
\hline $\begin{array}{l}\text { 3. Lack of interest in } \\
\text { contact }\end{array}$ & $.27^{* * *}$ & $.17 * * *$ & - & .16 & $.18^{*}$ & $.17 *$ & $-.23 * *$ & -.09 & .16 & .11 & .06 & $.28 * * *$ & -.11 \\
\hline $\begin{array}{l}\text { 4. Attribution of fear of } \\
\text { appearing racist } \\
\text { (majority)/Attribution of } \\
\text { fear of discrimination } \\
\text { (minority) }\end{array}$ & $.23 * * *$ & .04 & $.13^{* *}$ & - & $.34 * * *$ & $.27 * * *$ & -.04 & -.02 & .07 & -.05 & .02 & $.19^{*}$ & -.09 \\
\hline $\begin{array}{l}\text { 5. Attribution of fear of } \\
\text { being rejected }\end{array}$ & $.28 * * *$ & .02 & $.14^{* *}$ & $.64 * * *$ & - & $.21 *$ & -.01 & .01 & .12 & -.07 & .14 & .07 & -.06 \\
\hline $\begin{array}{l}\text { 6. Attribution of lack of } \\
\text { interest in contact }\end{array}$ & .01 & $.12 *$ & $.20 * * *$ & $.17 * * *$ & $.12 *$ & - & $-.18^{*}$ & -.03 & $.22 * *$ & $.19^{*}$ & -.00 & -.00 & -.16 \\
\hline 7. Contact quality & $-.14 * *$ & .06 & $-.40 * * *$ & -.05 & -.05 & $-.14 * *$ & - & $.52 * * *$ & .09 & -.13 & $.21^{*}$ & .00 & $.37 * * *$ \\
\hline 8. Contact quantity & -.09 & .05 & $-.25 * * *$ & .01 & .01 & .04 & $.31 * * *$ & - & .14 & -.08 & $.27 * * *$ & .05 & $.19 *$ \\
\hline 9. Individuals & .09 & .08 & .09 & .02 & .07 & -.02 & $-.11 *$ & $-.13 * *$ & - & $.37 * * *$ & $.17 *$ & $.32 * * *$ & -.04 \\
\hline 10. Two groups & $.16^{* *}$ & .03 & $.32 * * *$ & $.18 * * *$ & $.23 * * *$ & $.17 * * *$ & $-.43 * * *$ & $-.13 * *$ & $.16^{* *}$ & - & $-.26 * *$ & $.23 * *$ & -.07 \\
\hline 11. One group & -.07 & -.01 & $-.22 * * *$ & -.02 & -.04 & -.08 & $.40^{* * *}$ & $.14^{* *}$ & -.01 & $-.44 * * *$ & - & $.23 * *$ & .16 \\
\hline 12. Dual identity & $.18^{* * *}$ & $.10^{*}$ & $.20 * * *$ & $.20 * * *$ & $.18 * * *$ & $.17^{* * *}$ & $-.18 * * *$ & .01 & .09 & $.39 * * *$ & $-.16^{* * *}$ & - & .01 \\
\hline 13. Outgroup attitudes & $-.19 * * *$ & -.04 & $-.50 * * *$ & -.05 & -.05 & $-.24 * * *$ & $.53 * * *$ & $.28 * * *$ & $-.11 *$ & $-.39 * * *$ & $.42 * * *$ & $-.13 * *$ & - \\
\hline
\end{tabular}


Table 3. Indirect effects in the tested models for the Italian sample $(N=400)$. Only significant indirect effects are shown.

\begin{tabular}{|c|c|c|c|c|}
\hline Predictor & Indirect process & Criterion variable & $\begin{array}{c}\text { Mean bootstrap } \\
\text { estimate }\end{array}$ & $\begin{array}{c}\text { Percentile } \\
\text { confidence } \\
\text { interval }(95 \%)\end{array}$ \\
\hline Fear of being rejected & Contact quality & Outgroup attitudes & 0.0434 & {$[0.0146,0.0864]$} \\
\hline $\begin{array}{l}\text { Lack of interest in } \\
\text { contact }\end{array}$ & Contact quality & Outgroup attitudes & -0.0910 & {$[-0.1470,-0.483]$} \\
\hline Fear of being rejected & $\begin{array}{c}\text { Contact quality }- \text { one } \\
\text { group }\end{array}$ & Outgroup attitudes & 0.0106 & {$[0.0035,0.0241]$} \\
\hline $\begin{array}{l}\text { Lack of interest in } \\
\text { contact }\end{array}$ & $\begin{array}{c}\text { Contact quality }- \text { one } \\
\text { group }\end{array}$ & Outgroup attitudes & -0.0225 & {$[-0.0425,-0.0098]$} \\
\hline Fear of being rejected & Contact quality & Individuals & -0.0321 & {$[-0.800,-0.080]$} \\
\hline $\begin{array}{l}\text { Lack of interest in } \\
\text { contact }\end{array}$ & Contact quality & Individuals & 0.0676 & {$[0.0181,0.1326]$} \\
\hline Fear of being rejected & Contact quality & Two groups & -0.0900 & {$[-0.1652,-0.0324]$} \\
\hline $\begin{array}{l}\text { Lack of interest in } \\
\text { contact }\end{array}$ & Contact quality & Two groups & 0.1894 & {$[0.1215,0.2819]$} \\
\hline Fear of being rejected & Contact quality & One group & 0.0883 & {$[0.0316,0.1707]$} \\
\hline $\begin{array}{l}\text { Lack of interest in } \\
\text { contact }\end{array}$ & Contact quality & One group & -0.1849 & {$[-0.2791,-0.1135]$} \\
\hline
\end{tabular}

Note. Mean bootstrap estimates are based on 5,000 bootstrap samples. 
Table 4. Indirect effects in the tested models for the immigrant sample $(N=141)$. Only significant indirect effects are shown.

\begin{tabular}{llccc}
\hline \multicolumn{1}{c}{ Predictor } & Indirect process & Criterion variable & $\begin{array}{c}\text { Mean bootstrap } \\
\text { estimate }\end{array}$ & $\begin{array}{c}\text { Percentile } \\
\text { confidence } \\
\text { interval (95\%) }\end{array}$ \\
\hline $\begin{array}{l}\text { Fear of being } \\
\text { discriminated }\end{array}$ & Contact quality & Outgroup attitudes & 0.0981 & {$[0.043,0.2922]$} \\
$\begin{array}{l}\text { Fear of being rejected } \\
\text { Lack of interest in } \\
\text { contact }\end{array}$ & Contact quality & Outgroup attitudes & -0.1269 & {$[-0.3147,-0.0104]$} \\
\hline
\end{tabular}

Note. Mean bootstrap estimates are based on 5,000 bootstrap samples. 
Figure 1. Structural equation model of the effects of antecedents of contact on outgroup attitudes via quality and quality of contact, and group representations, Italian sample $(N=400)$. 


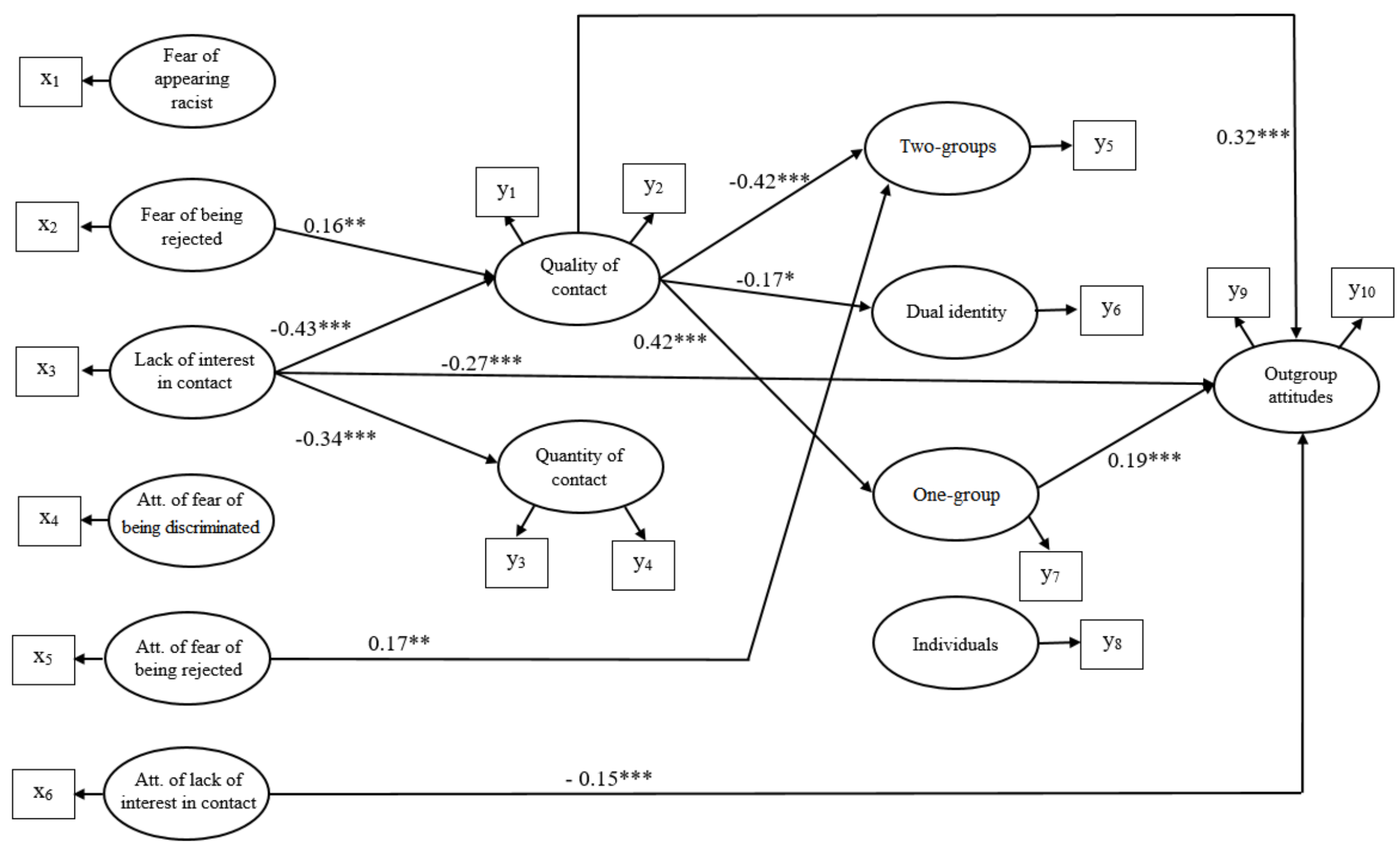

Note. Only significant parameters are presented. Att. = Attributions. Significant correlations among same-level factors: fear of appearing racist with a) fear of being rejected $(r=$ $\left..17^{* * *}\right)$, b) lack of interest in contact $(r=.27 * * *)$, c) attributions of fear of being discriminated $\left(r=.23^{* * *}\right)$ d) attribution of fear of being rejected $\left(r=.28^{* * *}\right)$; fear of being rejected with a) lack of interest in contact $\left(r=.17^{* * *}\right)$, b) attribution of lack of interest in contact $(r=.12 *)$; lack of interest in contact with a) attribution of fear of being 
discriminated $\left(r=.13^{* *}\right)$, b) attribution of fear of being rejected $\left(r=.14^{* *}\right)$, c) attribution of lack of interest in contact $\left(r=.20^{* * *}\right)$; attribution of fear of being rejected with a) attribution of fear of being rejected $(r=.64 * * *)$, b) attribution of lack of interest in contact $(r=.17 * * *)$; attribution of fear of being rejected with a) attribution of lack of interest in contact $\left(r=.12^{* *}\right)$. Contact quality with contact quantity $\left(r=.26^{* * *}\right)$. Separate individuals with a) two groups $\left(r=.15^{*}\right)$; two groups with a) one group $\left(r=-.39^{* * *}\right)$, b) dual identity $\left(r=.37^{* * *}\right)$.

$* p<.05 ; * * p<.01 ; * * * p<.001$. 
Figure 2. Structural equation model of the effects of antecedents of contact on outgroup attitudes via quality and quality of contact, and group representations, immigrant sample $(N=141)$.

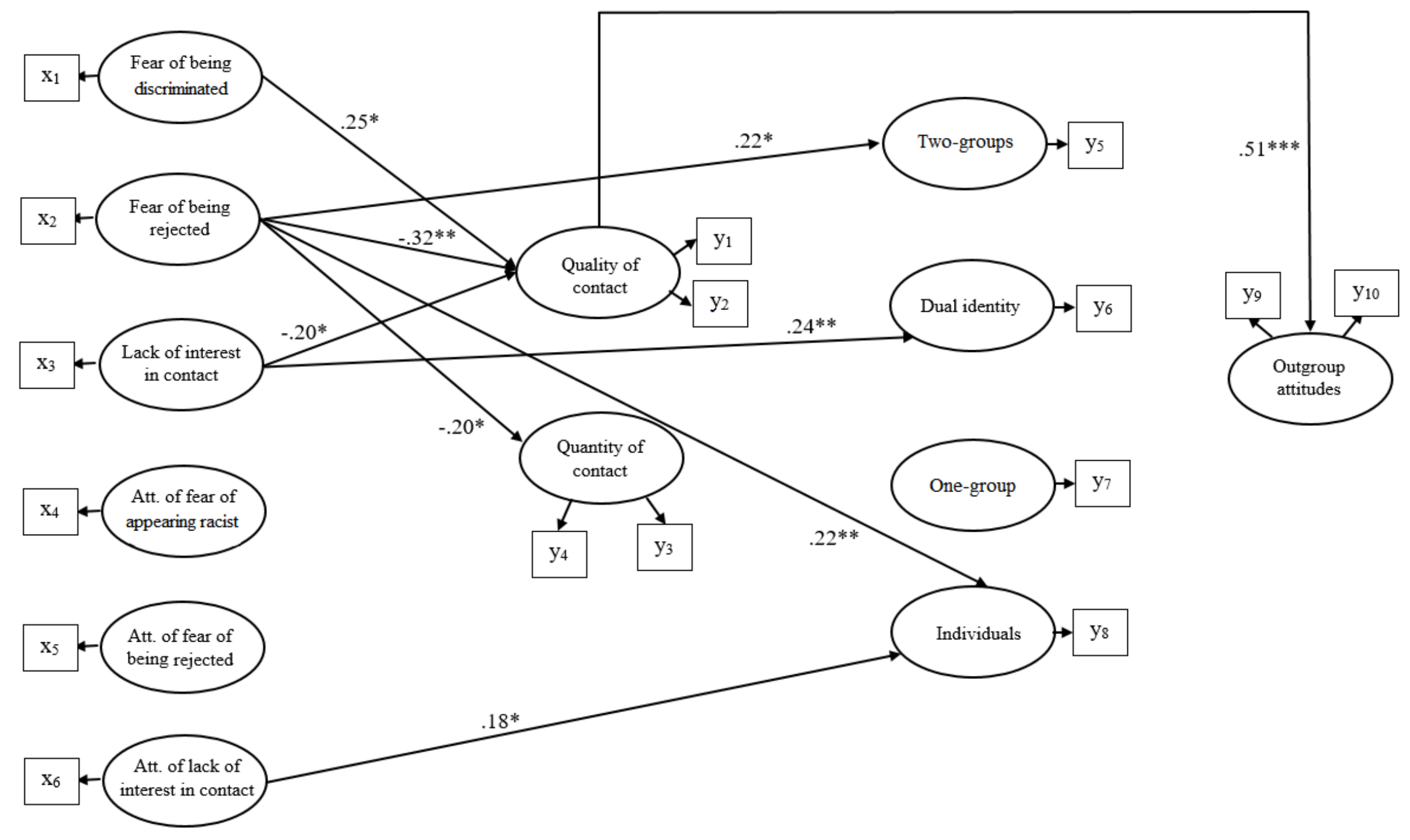


Note. Only significant parameters are presented. Att. = Attributions. Significant correlations among same-level factors: fear of being discriminated with a) fear of being rejected $\left.\left(r=.46^{* * *}\right), \mathrm{b}\right)$ lack of interest in contact $\left.(r=.23 * *), \mathrm{c}\right)$ attribution of fear of appearing racist $(r=.28 * * *)$, d) attribution of lack of interest in contact $(r=.30 * * *)$; fear of being rejected with a) lack of interest in contact $(r=.30 * * *)$, b) attribution of fear of appearing racist $(r=.23 * *)$, c) attribution of lack of interest in contact $(r=.33 * * *)$; lack of interest in contact with a) attribution of fear of being rejected $\left(r=.18^{* *}\right)$, b) attribution of lack of interest in contact $(r=.17 * *)$; attribution of appearing racist with a) attribution of being rejected $(r=.34 * * *), b)$ attribution of lack of interest in contact $(r=.27 * * *)$; attribution of fear of being rejected with a) attribution of lack of interest in contact $(r=.21 *)$.

Contact quality with contact quantity $(r=.52 * * *)$. Separate individuals with a) two groups $(r=.30 * * *)$, b) dual identity $(r=.24 * *)$; two groups with a) one group $(r=-.20 * *)$, b) dual identity $\left(r=.20^{* *}\right)$; one group with a) dual identity $\left(r=.21^{* *}\right)$.

$* p<.05 ; * * p<.01 ; * * * p<.001$ 
